\title{
The Impact of Collaborative Task on the FL Vocabulary Acquisition
}

\author{
Bahador Sadeghi ${ }^{1}$, Roya Safari ${ }^{2}$ \\ ${ }^{1}$ Assistant professor, English Department, Islamic Azad University, IRAN \\ ${ }^{2}$ Applied Linguistics, English Department, Islamic Azad University, IRAN
}

\begin{abstract}
Previous literature has revealed that collaborative manner of learning improves the second language acquisition. The present study was conducted to investigate the effect of a collaborative learning task compared to direct method on the FL vocabulary acquisition. To this end, two groups of intermediate EFL learners $(\mathrm{N}=38)$ were treated through collaborative task and direct method respectively. The learners were subjected to a pretest, a Snowball task and a direct method, and a post test over a period of one month. The result of T-test data analysis revealed that collaborative learning task played a significant role in improving learner's vocabulary knowledge, and there was significant difference between the present collaborative learning task and direct learning method .Therefore, the findings of this study have implications for teachers, learners, and syllabus and textbook designers .
\end{abstract}

Keywords: Collaborative task, Direct method, Receptive vocabulary, Snowball

\section{INTRODUCTION}

In collaborative learning context, learners are engaged in an activity through which they can share their ideas, knowledge, and words in order to achieve the common goal (Brufee, 1999). This learning context provides a rich feedback environment for learners and facilitates language acquisition. A language component which plays the significant role in communication competence is vocabulary (Coady, Huckin, 1997). Vocabulary can be acquired subconsciously while learners are engaged in a collaborative learning activity which provides an opportunity for learners to interact together (Nuan, Schmidit, 1989). Group collaboration allows learners to notice their linguistic gap, note the link between form and meaning, and get feedback from their peers (Swain, 2000). Direct method may be easier to apply in the class than collaborative task, but the significant role of interaction, rich feedback environment, and scaffolding should not be neglected. Swain (1985) claims that the major problem is not to have enough opportunity to get involved in a mutual negotiated interaction in the passive environment of teacher-centered classrooms. A student-centered classroom plays a significant role in improving the English proficiency and motivation of learners. The purpose of the present study, therefore, was to investigate the impact of collaborative task on the FL vocabulary acquisition of intermediate Iranian learners. 
It attempted to answer the following research questions:

Is there any significant difference in the effect of a collaborative learning Task

(Snowball) and a Direct method on the receptive vocabulary knowledge?

\section{ReView of ReLATEd Literature}

In Collaborative learning context, learners play the main role in their learning process and interact with each other in order to acquire the same goal, and the teacher's role is to facilitate their learning (Oxford, 1997). Indeed, the essence of learning comes from not just the learner's head, but also from the process of engagement between learner and other people and their social context (Hewitt \& Scardamalia, 1998). In Vygotsky's view (1987), interaction between learners and scaffolding and getting support from all resources facilitates learning.Recent SLA research has demonstrated a need for classroom activities where students are responsible for one another's learning as well as their own. In fact, knowledge is constructed and transformed by students. Moreover, they retain the information longer and also appear more satisfied with their classes (Bechman, 1990; Goodsell, Maher, Tino et al. 1992). The proponents of collaborative tasks believe this fact that students are actively exchanging, debating, and negotiating ideas within their group increases their interests in learning (Totten, Sills, Digby, \& Russ, 1989). In order to learn new information, ideas and skills, students have to work actively and integrate new material with what they already know or use it to recognize what they knew. The main feature of collaborative learning is that it allows students to talk with each other and to maximize their own and each other's learning.The theories associated with collaborative learning have originated from three psychologists and researchers' views: Vygotsky, Piaget, and Bandura.

The Vygotskian Perspective implies to a social interaction aspect that particularly emphasizes the social context of learning (William \& Burden, 1997).To Vygotsky (1987), good learning occurs during interaction around the zone of proximal development of learners. The Piagetian Perspective placed special emphasis on biology in terms of developmental stage and implied that learning is the result of cognitive development. Thus, the active participation of learners during learning is an essential component in order to construct their knowledge (Sigel \& Cocking, 1977). Bandura's Social Learning Theory holds that learning occurs in a social context and highlights the social behavior of participants involved in reciprocal interaction including observation, behavior modeling, emotional reaction, motivation, and receiving reinforcement. In fact, the theory entails both cognitive and behavioral aspects (Bandura, 1977). collaborative methods facilitate second language learning, for the learner distinguishes their knowledge gap and try to test and revise their hypotheses(Swain, 2001).

As mentioned earlier, what distinguishes collaborative learning from traditional learning is the active engagement of learners. This active learning encompasses five features: Positive interdependence, Individual accountability, Face-to-face interaction, Interpersonal, and small-group skills learning,Group processing.There are many collaborative learning techniques which differ from one another in nature, but all emphasize the importance of face-to-face interaction in mutual understanding. Some such techniques are Syndicates, Think-pair share, Dyadic, Snowball, Seminar, Round Robin, Fish bowl, Buzz group, and Jigsaw. One collaborative technique was employed in the present study, and will be discussed in the next part of this study.Based on the numerous studies which support the use of collaborative learning, it can be said that collaborative learning techniques promote the rate of language learning and enhance learner achievement. Moreover, while learners are engaged in collaborative learning, they may acquire language skills and components 
spontaneously. Learners act as a resource of information for each other (McGroarty, 1989).Therefore, the use of collaborative learning techniques enhances the cognitive and affective aspects of learning (Johnson, Johnson, 2000).

\section{Previous Studies of Collaborative Learning and Vocabulary Acquisition}

A number of studies have investigated the impact of collaborative learning on vocabulary acquisition (e.g., Luan, Sappathy, 2011; Kim, 2008; Hwang , 2002; Newton, 2001; Kowal , Swain ,1994). Luan and Sappathy (2011) investigated the impact of negotiated interaction on L2 vocabulary acquisition. A total of 48 participants with the same first language membership at a primary school were divided into two groups. One group was engaged in an information-gap two-way interactive task, and the other group was taught using traditional methods or a oneway input task. The comparison of the pre-test and post-test scores revealed that learners engaged in two-way interaction gained higher scores on the vocabulary test.

Kim (2008) examined the effect of collaborative and individual tasks on the acquisition of L2 vocabulary by comparing the performance of learners on a dictogloss task. The first group of participants was involved in individual work, but the other group was engaged in pair work. The results showed significant effect of collaborative work on vocabulary acquisition. Kim (2008) investigated the effect of collaborative work on L2 vocabulary acquisition and obtained similar results in support of the effect of scaffolding on language learning. To sum up, the present study provides support for previous studies and attempts to explore the effect of collaboratrive instructional treatment on vocabulary knowledge of learners.

Hwang (2002) examined the impact of negotiated interaction on L2 vocabulary acquisition of Korean beginner learners, and found that the negotiated interaction group gained more vocabulary than the non-negotiated interaction group.

Newton (2001) suggested vocabulary learning through communication tasks. Learners were exposed to new words during interaction in a cooperative context. As a result of this treatment, not only rich language use was attained, but also the meanings of most words were retained for a long period of time.

Kowal and Swain (1994) examined the effect of dictogloss on second language learning by engaging a group of intermediate and advanced learners of French in reconstructing a text after they first listened to it. The results revealed that learners noticed their linguistic gap, linked form and meaning, and received feedback from their peers during group collaboration. The experimental group outperformed the control group.

\section{MetHOD}

\section{Participants}

The participants in this study were 38 Persian-speaking learners of English as a Foreign Language enrolled in a discussion class at English language Institute of Jahad Daneshgahi in Qazvin, aging from 24 to 30, they were screened from among a total of 80 students based on their scores on the vocabulary section of a Michigan general proficiency test. Indeed, the participants who scored more than one standard deviation above and below mean were excluded from the study. The subjects were at the intermediate level. The selected subjects were placed into two groups to receive different treatments. The first group, with 20 members, was instructed through the Snowball task. The second group, which contained 18 members, was exposed to the the Direct teacher-centered class method. 


\section{Materials and Instruments}

Vocabulary section of a Michigan general proficiency test (2009): This was a 40-item multiple-choice test which was administered to the homogenize sample. The time allocation for the test was 35 minutes.

A pretest consisting of 80 vocabulary items: For each of the eight topics to be discussed in the experiments, 10 essential words were chosen. These words were then placed and underlined in a series of 80 sentences. The learners were given about 45 minutes to write the Persian meaning of each word. The purpose was to know which of the words the test takers were already familiar with. These words were excluded from the posttest. A posttest was administered at the end of the treatment. The questions on this test came from the words used by the students during class discussions. The words the learners identified in the pretest were excluded from the posttest. The posttest consisted of 30 multiple-choice question items intended to measure receptive vocabulary knowledge. 25 minutes was allotted for the posttest.

\section{Snow ball}

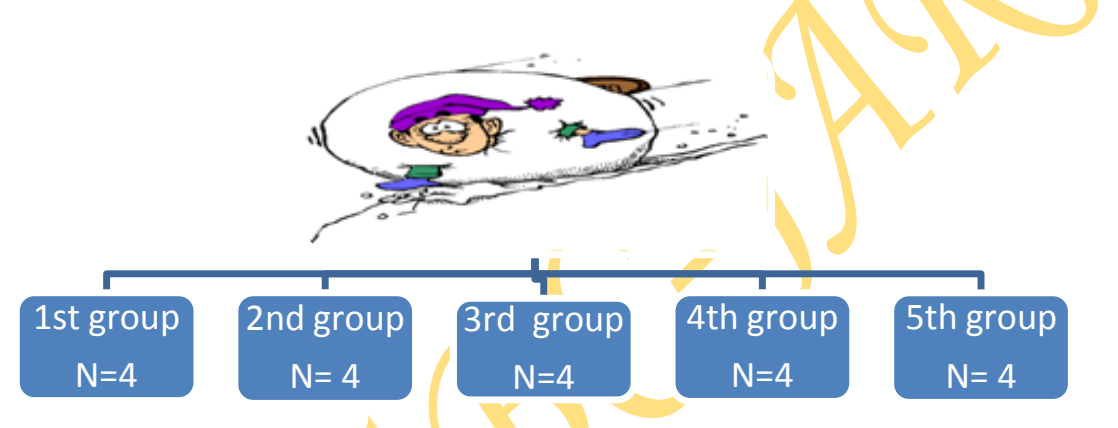

\section{Procedures}

Once the pretest was given to all the students, one of the groups was treated with collaborative task (Snowball), and the second group with Direct English language class method. Each class met two sessions a week for one month: 8 sessions in all. The same teacher taught the same materials to the two classes. In a scene-setting session before the Snowball treatment actually had begun, the teacher explained the whole procedure to the students and listed the topics to be worked out in each session. At the beginning of each session, some words were placed on the board to help the students with the discussion. These included the words given on the pretest. The posttests were administered in the tenth session.For the Snowball, the students were divided into five groups of four. The learners in each group were seated in a row. The teacher first asked a question related to the topic at issue and allowed the students in all groups to work out the response for a few minutes. Then, in each group the student sitting on the far left side replied to the question. The teacher put this answer on the board for other students to see. Then, the second question was posed by the teacher, to be answered by the second student in each group. This procedure was repeated for the remaining group members. In the end, the teacher asked some students to elaborate the responses they had previously provided. 

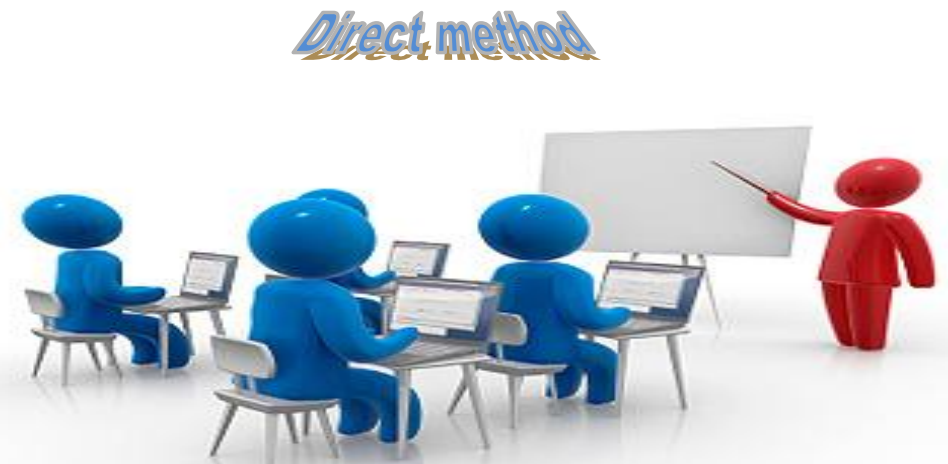

For the Direct English language class method, at first, the teacher listed the topics to be worked out in each session and placed related words to the topic at issue on the board in order to be presented to the students. These included the words given on the pretest.The teacher asked a question related to the topic at issue, and then, each learner tried to answer by using received vocabulary knowledge directly through teacher. In keeping with individual learning, each learner tried to achieve a goal individually. At the end of the treatment, the posttest was administered to the two experimental groups in order to measure the students' knowledge of receptive vocabulary.

\section{Data ANALYSIS}

The student responses were scored, and the data were submitted to the SPSS statistical package for analysis. It is worth noting at this point that the reliabilities of the receptive posttest was estimated to be 0.64 , employing the KR-21 formula.

\section{Results}

The present study investigated the effect of an independent variable with two levels (Snowball task, Direct method) on a dependent variable (receptive vocabulary learning). For this purpose, a T-Test procedure was employed to analyze the posttest scores.

\section{Response to the Research Question}

The research question investigated the effect of Snowball technique, and the Direct method on the receptive vocabulary acquisition by intermediate Iranian learners. The descriptive statistics are given in Table 1.

Table 1 Descriptive statistics for the two experimental groups (performance on a test of receptive vocabulary Group Statistics)

\begin{tabular}{|l|l|l|l|l|}
\hline \multicolumn{2}{|c|}{ N } & Mean & Standard Deviation & Standard Error \\
\hline Snow Ball & 20 & 22.75 & 1.55 & .34 \\
\hline Direct Method & 18 & 15.89 & 2.29 & .54 \\
\hline
\end{tabular}

From these descriptive data, it can be seen in this table that the Snow ball group earned the higher mean, and the group subjected to Direct method ended up with the lower mean. So, the Snowball group performed much better than the Direct Method. However, to make sure these observations are also statistically significant, a T-Test was run, with probability level set at $\mathrm{p}=$ or $<0.05$. The results are presented in Table 2 . 
Table 2 Results of the T-Test comparison of means for learners' receptive vocabulary knowledge Independent Samples Test

\begin{tabular}{|l|c|c|c|c|c|c|c|}
\hline & \multicolumn{7}{|c|}{$\begin{array}{c}\text { Levene's Test for Equality of Variances } \\
\text { 95\% Confidence Interval of the Difference } \\
\text { t-test for Equality of Means }\end{array}$} \\
\hline & $\mathrm{F}$ & Sig. & $\mathrm{t}$ & $\mathrm{df}$ & $\begin{array}{c}\text { Sig. } \\
(2-\text {-tailed })\end{array}$ & $\begin{array}{c}\text { Mean } \\
\text { Difference }\end{array}$ & $\begin{array}{c}\text { Standard } \\
\text { Error }\end{array}$ \\
\hline $\begin{array}{l}\text { Equal variances assumed } \\
\text { Equal variances not assumed }\end{array}$ & 2.13 & .15 & 10.88 & 36 & .00 & 6.86 & .63 \\
\cline { 2 - 9 } & & & 10.66 & 29.38 & .00 & 6.86 & .64 \\
\hline
\end{tabular}

* The mean difference is significant at the 0.05 level

In order to examine whether the difference between the two experimental groups is statistically significant, the researchers administered a T-test for the data. As with the results obtained in the test of Levene for Equality of Variances, the variances in both groups werenot equal. Sig. value (p) was lower than .05. It can be also seen in the table of t-test for equality of means that the group means were statistically significant. The value in the Sig. (2-tailed) was below .05, therefore, there was a great statistically significant difference between Snowball Group and the group treated with Direct method.

\section{DISCUSSION}

The present study examined the effect of the collaborative learning task ( Snowball), and Direct learning method on the acquisition of receptive English vocabulary by Intermediate Iranian learners. Regarding the research question, the statistical analysis showed that the learners acquired receptive vocabulary much more significantly through Snowball task than the Direct method. This is in line with the finding of Ellis (2003) that engaging learners in a pedagogical task other than the PPP instruction activates processes that promote L2 learning. The Snowball technique led to the great degree of acquisition of receptive vocabulary. A number of reasons can be given for this finding. The Snowball turned out to be effective task most probably because it demands interaction among learners and creates a more enjoyable learning context. The placement of learners in the instructional groups required by the Snowball task provides a rich feedback context. The underlying reason for the positive role of the Snowball task in improving receptive vocabulary acquisition lies in the fact that the learners were engaged in the production activity, gained feedback from the responses of other students to the same question, and checked the written forms of the responses. All this led the learners to better notice new vocabulary and to find out about their knowledge gap. The finding is consistent with Kim's (2008) study in which a collaborative group outperformed an individual group in terms of vocabulary acquisition.

\section{CONCLUSION AND IMPLICATIONS}

In conclusion, this study compared the affects of two types of methods on the learners' receptive vocabulary knowledge. The findings showed that the difference between the Snowball task, and the Direct method was significant. Snowball group was a more effective task than the Direct method in terms of receptive vocabulary acquisition by intermediate learners. Therefore, it can be concluded that collaborative learning task has a significant effect on the receptive vocabulary learning of intermediate learners. The results of the present study provide implications for syllabus and English book designers, who try 
to design textbooks. Moreover, the findings of the present study promote the learners' knowledge of different role of teacher and students in both teaching context. The results of this study also have implications for learners. Students can benefit from the advantages of collaborative task. The replication of this study can be conducted on the effect of this collaborative task on other language components and skills. Also comparison among collaborative tasks can be made according to the gender and age differences of learners.

\section{REFERENCES}

Bandura, A. (1977). Social Learning Theory. New York: General Learning Press.

Beckman, M. (1990). Collaborative Learning: Preparation for the Workplace and Democracy, College Teaching, 38(4), 128-133.

Bruffee, K. A. (1999). Collaborative learning: Higher education, interdependence, and the authority of knowledge (2nd ed.). Baltimore: John Hopkins University Press.

Coady, J.,\& Huckin, T. (Eds.) (1997). Second language vocabulary acquisition. A rationale for pedagogy. Cambridge: Cambridge University Press.

Ellis,R.(2003). Task-based language learning and teacging. Oxford Unuversity Press.

Goodsell, A., Maher, J., Tinto, V. et al. (1992). Collaborative Learning: A Sourcebook for Higher Educarion. National Center.

Hewitt, J., \& Scardamalia, M. (1998). Design principles for the support of distributed processes, Educational Psychology Review, 10(1), 75-95.

Johnson, D. W., \& Johnson, R. (2000). Cooperative learning, values, and culturally plural classrooms, In M. Leicester, C. Modgill, \& S. Modgill (Eds.), Values, the classroom, and cultural diversity (pp. 15-28). London: Cassell PLC.

Jung,K.(2004). L2vocabulary development through conversation: A conversation Analysis. Second Language studies,23(1),27-66.

Kim,k.(2008). The contribution of collaborative and individual tasks to the acquisition of L2 vocabulary. The Modern Language Journal,92(1),114-130.

Luan,N.L.,\&Sappathy,S.M.(2011). L2vocabulary acquisition: The Impact of Negotiated Interaction.GEMA Online TM Journal of language studies,11(2).1675-8021.

McGroarty,M.(1989). The benefit of cooperative learning arrangements in second language instruction. National Associatin for Bilingual Association Journal, 13,127-143.

Mohamed,A.A.A.(2009). Investigating incidental vocabulary acquisition in ESL conversation classes.MA Thesis ,University of North Texas .

Newton, J. (2001). Options for assisting vocabulary learning in communication tasks, ELT Journal, $55(1), 30-37$.

Nunan,D. (1989). Designing Tasks for the communicative classroom. Cambridge: Cambridge University Press.

Oxford, R. (1997), Cooperative Learning, Collaborative Learning, and Interaction: Three Communicative Strands in the Language Classroom. Modern Language Journal, 81(4), 443-456.

Sigel, I.,\&Cocking, R.( 1977). Cognitive Development from Childhood to Adolescence: A Constructivist Perspectives, NY: Holt, Rinehart and Winston.

Swain, M. (2001). Integrating Language content teaching through collaborative tasks. Canadian Modern Language Review, 58,44-63.

Totten, S., Sills, T., Digby, A., \& Russ, P. (1991). Cooperative learning: A guide to research, New York: Garland.

Vygotsky, L. S. (1987). The collected works of L. S. Vygotsky (R. W. Rieber \& A. S. Carton, Eds.). New York: Plenum.

Williams, M. ,\& Burden, R.L. (1997). Psychology for Language Teachers: A Social Constructivist Approach. Cambridge: Cambridge University Press. 